\title{
Application of the Leslie Matrix to Predict the Number and Growth Rate of Women in West Java 2021
}

\author{
Ati Maryati ${ }^{1}$, Sudradjat Supian $^{1}$ and Subiyanto ${ }^{2}$ \\ ${ }^{I}$ Department of Mathematics, Faculty Of Mathemathic and Natural Science, Universitas Padjadjaran Indonesia \\ ${ }^{2}$ Department of Marine Sciences, Faculty of Fishery and Marine Sciences,Universitas Padjadjaran, Indonesia. \\ Corresponding author e-mail address: ati19002@mail.unpad.ac.id
}

\begin{abstract}
Data from the Central Statistics Agency 2019 collected that the total population of women in Indonesia is less than male, which is 131.48 million people if compared to the total male population, which is 132.68 million population. This matter is directly relation to the total female population in West Java which is also less than the male population around 24031252.0 female and 24652609.0 male population(Badan Pusat Statistika, 2019).This should be the focus of the government to balance the population growth of women and men in West Java because of the role of women being central in the population growth of the people of West Java. The targets of the development plan contained in the RPJM 2005-2025 is to improve the quality of human resources, including the role of women in development. The growth of the female population is an important thing that must be observed, considering the role of women is determining the development of the human population in the future, because without the role of women the population will not be able to develop. This encourages researchers to predict the number and rate of female population growth in West Java in 2021. The Leslie matrix is a matrix used to predict the number and growth rate of a population. By applying the Leslie matrix to predict the number and growth rate of women in West Java in 2021, it can be concluded that the number of female populations in West Java is around tends to increase.
\end{abstract}

Keywords: Eigen values, Leslie matrix, Population.

\section{Introduction}

In our daily life, we cannot be separated from mathematics. Applied mathematics is a very interesting field to study. In applied mathematics, mathematical concepts are studied and their application to solved the problem in real life. The problem that has been encountered in the field of population is the problem of population growth. The growth of a population is characterized by a change in the number of a population (Coccia, 2018). Population changes are influenced by the internal conditions of the population itself, which is births, deaths and life survival. Population growth can provide information on whether changes in population numbers for the following year always increase, decrease or remain. Therefore, the Leslie matrix is used as a population growth model to determine the number prediction and growth rate prediction of a population for the following year (Chandler et al., 2004; Rand et al., 2020; Li et al., 2018).

Leslie matrix model is a model used by demographers to predict the number and growth rate of a population (Anggreini, 2017; Hansen, 1989; Smit et al., 2006). The resulting model has the ability to 
predict population-level outcomes, such as total population size, population recruitment, or population loss due to density dependence at each time step interval (Miller et al., 2020).The Leslie matrix can provide an overview of the growth process dynamics of a population, for example long-term population growth, population distribution in the age groups in long-term and its application in policy making of developed population (Carnia et al., 2019).

The Leslie matrix is a matrix used to predict the number and growth rate of a population. In population growth, there are several factors that very give effect, which is the level of fertility, the level of life survival and the age range of the population. This population growth can provide information on how much changes in population numbers for the next year (Marzuki et al., 2017). Data from the Central Statistics Agency 2019 collected that the total population of female in Indonesia is less than male which is 131.48 million people if compared to the total male population which is 132.68 million people. According to data obtained from the Central Statistics Agency of West Java Province, the total female population in West Java Province is also smaller than the male population, which is 24031252.0 for female and 24652609.0 for male. This is directly proportional to the total population of Indonesia, which has a lower female population than the male population. This should be the focus of the government to balance the population growth of female and male in West Java because the role of women being central in the population growth of the people in West Java. The targets of the development plan contained in the 2005-2025 RPJM is to improve the quality of human resources including the role of women in development (BPS, 2019). The growth of the female population is an important thing that must be observed, considering the role of women is determining development the human population in the future, because without the role of women, the population will not be able to develop (Marzuki et al., 2017). Research using the Leslie Matrix on fertility has been carried out in China which aims to determine the impact of changes in fertility policy in China on the UEBMI fund balance. On the background of the research, because China's fertility rate continues to decline, China's population shows some new features. First of all, the proportion of the population of working age starts to decline and is accompanied by a gradual decrease in the demographic bonus. In addition, the rate of growth of the elderly population in China is accelerating and as a result the proportion of the elderly population continues to increase (Xie et al., 2020). Another study using the nonlinear Leslie matrix in environmental assessment models. which aims to simulate the effects of stress on biological populations and take into account the biotic potential growth of the population and environmental resistance (Monte, 2018). In addition, there is also a study using the Leslie matrix model as a discrete model for the female population in Indonesia, Trenggalek Regency. The discrete model was divided into fourteen age intervals constructed using birth rates and life expectancy.

In this study, the number and rate of female populations growth in West Java Province will be predicted in 2021 using the leslie matrix.

\section{Materials and Methods}

\subsection{Materials}

In this study, we use secondary data obtained from the Central Statistics Agency (BPS) of West Java Province. Data on the population of West Java Province by age group and sex in 2018 and 2019. Complete data can be seen in Table 1(BPS, 2019).

Table 1. Population of West Java Province by age group and sex in 2018 and 2019. 


\begin{tabular}{ccccc}
\hline \multirow{2}{*}{ Age Group } & \multicolumn{2}{c}{ Year of 2018 } & \multicolumn{2}{c}{ Year of 2019 } \\
\cline { 2 - 5 } & Male Population & $\begin{array}{c}\text { Female } \\
\text { Population }\end{array}$ & Male Population & $\begin{array}{c}\text { Female } \\
\text { Population }\end{array}$ \\
\hline $\mathbf{0}-\mathbf{4}$ & 2219108.0 & 2124452.0 & 2210857.0 & 2115954.0 \\
\hline $\mathbf{5}-\mathbf{9}$ & 2207857.0 & 2104541.0 & 2220399.0 & 2122338.0 \\
\hline $\mathbf{1 0 - 1 4}$ & 2127509.0 & 2016745.0 & 2137707.0 & 2023494.0 \\
\hline $\mathbf{1 5}-\mathbf{1 9}$ & 2109814.0 & 2021765.0 & 2109794.0 & 2020185.0 \\
\hline $\mathbf{2 0}-\mathbf{2 4}$ & 2092684.0 & 2030744.0 & 2105160.0 & 2039168.0 \\
\hline $\mathbf{2 5}-\mathbf{2 9}$ & 1998299.0 & 1954176.0 & 2011048.0 & 1971289.0 \\
\hline $\mathbf{3 0}-\mathbf{3 4}$ & 1926606.0 & 1886055.0 & 1939901.0 & 1893803.0 \\
\hline $\mathbf{3 5}-\mathbf{3 9}$ & 1894696.0 & 1881773.0 & 1898998.0 & 1885988.0 \\
\hline $\mathbf{4 0}-\mathbf{4 4}$ & 1821266.0 & 1773433.0 & 1839707.0 & 1802637.0 \\
\hline $\mathbf{4 5}-\mathbf{4 9}$ & 1641396.0 & 1577476.0 & 1678203.0 & 1617102.0 \\
\hline $\mathbf{5 0}-\mathbf{5 4}$ & 1379269.0 & 1332937.0 & 1426780.0 & 1377890.0 \\
\hline $\mathbf{5 5}-\mathbf{5 9}$ & 1105765.0 & 1079022.0 & 1146119.0 & 1122713.0 \\
\hline $\mathbf{6 0}-\mathbf{6 4}$ & 843200.0 & 809776.0 & 882308.0 & 856075.0 \\
\hline $\mathbf{6 5}-\mathbf{6 9}$ & 569624.0 & 562.852 .0 & 605934.0 & 593587.0 \\
\hline $\mathbf{7 0}-\mathbf{7 4}$ & 355017.0 & 397213.0 & 372746.0 & 413028.0 \\
\hline $\mathbf{7 5 +}$ & 360499.0 & 476292.0 & 377040.0 & 498760.0 \\
\hline Total & 24652609.0 & 24031252.0 & 24962701.0 & 24354011.0 \\
\hline
\end{tabular}

\subsection{Methods}

This research is included in the category of applied research where the Leslie Matrix model is applied in the demographic field (Sanusi \& Ridiawati, 2018), which is to predict the number and rate of population growth in West Java Province. Based on the 2018 and 2019 population data obtained from the Central Statistics Agency, it is then entered into the Leslie Matrix model to see whether the population growth rate is increasing, constant or decreasing. In order to achieve the research objectives listed in the introduction, the research implementation procedure adopted is as follows:

1. Identify problems related to population growth and growth rate, then formulate problems and formulate research objectives and benefits obtained in this study.

2. Looking for references related to the object of research.

3. Data collection.

4. Data processing into population fertility rate data and population survival rate data.

\subsubsection{Leslie Matrix for Predicting the Total Growth of a Population}

The Leslie matrix is a matrix used to predict the number and growth rate of a population. Leslie matrix model that describes growth of an age-structured population (Mauritsson, 2019). This model explains the gender growth of the female population because the female population reproduces (Sanusi \& Ridiawati, 2018).

Some of the factors that influence population growth are fertility rates, survival rates and age ranges of the population. The population used as the initial population in the Leslie matrix projection is only the female population (Yuliawati et al., 2019). Uncertainty was introduced in the Leslie matrix (Cortes, 2020). Defined $a_{i}$ as the level of female fertility in age class $i$ which is the average number of children born in the age group at time $t$ per number of women in age class $i$. It is defined $b_{i}$ as the survival rate of women in age class $i$, which is the chance for women to survive from age class $i$ until $i+1$ at time to $t$. Here is the general form of the Leslie matrix is stated (Marzuki et al., 2017): 


$$
\begin{gathered}
L= \\
=\left[\begin{array}{ccccc}
a & a & \cdots & a_{n-1} & a_{n} \\
b_{1} & 0 & \cdots & 0 & 0 \\
0 & b & \cdots & 0 & 0 \\
\vdots & \vdots & \ddots & \vdots & \vdots \\
0 & 0 & \cdots & b_{n-1} & 0
\end{array}\right] \\
a_{i} \geq 0 \text { for } i=1,2,3 \ldots, n \\
0<b_{i} \leq 1 \text { for } i=1,2,3, \ldots, n-1
\end{gathered}
$$

Based on the problem boundary it is known that at least one age class of $a_{i}>0$, because if $a_{i}=0, \forall{ }_{i}$, then in that class no birth will occur. Age class that has a value of $a_{i}>0$, is called the fertility age class. It is known that $b_{i} \neq 0$, because if $b_{i}=0$ then no woman can survive in the next class.

In this model, women are divided into age classes for the same duration. For example, the maximum age attained by any woman in a population is A years, then the population is divided into $n$ age class. So, each class has a duration of $A / n$ years. The determination of these age classes can be seen in Table 1 .

Table 2. Determination of age class age

\begin{tabular}{cc}
\hline Age Class & Age Range \\
\hline 1 & {$\left[0, \frac{\mathrm{A}}{\mathrm{i}}\right)$} \\
2 & {$\left[\frac{\mathrm{A}}{\mathrm{i}}, \frac{2 \mathrm{~A}}{\mathrm{i}}\right)$} \\
3 & {$\left[\frac{2 \mathrm{~A}}{\mathrm{i}}, \frac{3 \mathrm{~A}}{\mathrm{i}}\right)$} \\
$\vdots$ & $\vdots$ \\
$\mathrm{i}-1$ & {$\left[\frac{(\mathrm{i}-2) \mathrm{A}}{\mathrm{i}}, \frac{(\mathrm{i}-1) \mathrm{A}}{\mathrm{i}}\right)$} \\
$\mathrm{i}$ & {$\left[\frac{(\mathrm{i}-1) \mathrm{A}}{\mathrm{i}}, \mathrm{A}\right]$} \\
\hline
\end{tabular}

For example, if the number of female population is known at each age of the $n$ class when $t=0$, and it is assumed that $n_{1}(t)$ is the total female population in the first age class, $n_{2}(t)$ total female population in the second age class, and so on until $n_{i}(t)$ is the number of female population in age class $i$, then the total population is (Sanusi \& Ridiawati, 2018):

$$
n(t)=n_{1}(t)+n_{2}(t)+n_{3}(t)+\ldots+n_{i}(t)
$$

Total population at each age at $t$ can be written

$$
n(t)=\left[\begin{array}{c}
n_{1}(t) \\
n_{2}(t) \\
n_{3}(t) \\
\vdots \\
n_{i}(t)
\end{array}\right]
$$

The vector $n(t)$ is called the initial age distribution vector 
For time $t+1$ with $n_{1}(t+1)$ is the total population in the first age class, $n_{2}(t+1)$ is the total population in the second age class, and so on until $n_{i}(t+1)$ is the total population in the age class $i$, then the total population is

$$
n(t+1)=n_{1}(t+1)+n_{2}(t+1)+n_{3}(t+1)+\ldots+n_{i}(t+1)
$$

The number of populations at each age at $t$ can be written

$$
n(t+1)=\left[\begin{array}{c}
n_{1}(t+1) \\
n_{2}(t+1) \\
n_{3}(t+1) \\
\vdots \\
n_{i}(t+1)
\end{array}\right]
$$

Defined at time $t+1$, the population in class 1 is:

$$
n_{1}(t+1)=a_{1} n_{1}(t)+a_{2} n_{2}(t)+a_{3} n_{3}(t)+\ldots+a_{i} n_{i}(t)
$$

If the total population at time $t$ for each age class reaches year $t+1$, then for the first age class the population at $t+1$ is the total number of people who were born and were at $t$. It is defined as the total population in the age class $i+1$ with $i=1,2,3, \ldots, n-1$ when time $t+1$ is the average number of people in age class $i$ at time $t$ that survives when time $t+1$. So that it can be written

$$
n_{i+1}(t+1)=b_{i} n_{i}(t), \quad i=1,2,3, \ldots, i-1
$$

Population in the second age class when $t+1$ is the population in the first age class at $t$ who can survive until $t+1$. The population in the third age class when $t+1$ is the population in the second age class at $t$ who can survive until $t+1$. And so on until the population in age class $i$ at $t+1$. So it can be established model of population growth:

$$
\left[\begin{array}{c}
n_{1}(t+1) \\
n_{2}(t+1) \\
n_{3}(t+1) \\
\vdots \\
n_{i}(t+1)
\end{array}\right]=\left[\begin{array}{ccccc}
a_{1} & a_{1} & \cdots & a_{i-1} & a_{i} \\
b_{1} & 0 & \cdots & 0 & 0 \\
0 & b_{2} & \cdots & 0 & 0 \\
\vdots & \vdots & \ddots & \vdots & 0 \\
0 & 0 & \cdots & b_{i-1} & 0
\end{array}\right]\left[\begin{array}{c}
n_{1}(t) \\
n_{2}(t) \\
n_{3}(t) \\
\vdots \\
n_{i}(t)
\end{array}\right]
$$

Or the growth model can be written as follows:

$$
n(t+1)=A n(t)
$$

Which is:

$n(t+1)$ : population vector containing the prediction of the population in the current class $t+1$. $A \quad$ : a Leslie Matrix with size $n x n$. . $n(t+1)$ : population vector containing the total population in the current age class $t, A x=\lambda x$ 
Definition 2.2.1.1(Sanusi \& Ridiawati, 2018)

If $A$ is a Matrix $n x n$, then a vector not zero $x$ on $R^{n}$ is called the eigenvector of $A$ if $A \boldsymbol{x}$ is a scalar multiple of $\boldsymbol{x}$.

For more details, see Equation (10).

$$
A x=\lambda x
$$

Which is:

$A$ : Matrix $n \times n$

$\lambda:$ the eigen value (eigen value) of $A$

$x$ : the eigenvector of $A$ which is related to $\lambda$ or is equivalent to Equation (11),

$$
(\lambda I-A) x=0
$$

In order for $\lambda$ to be an eigen value, there must be not zero solution of Equation (11), if and only if it satisfies Equation (12)

$$
\operatorname{det}(\lambda I-A) x=0
$$

\subsubsection{Leslie Matrix to Predict the Growth Rate of a Population}

\subsubsection{Eigen Values of the Leslie Matrix}

Equation (2.3) is only used to predict the amount of growth population whereas to predict the population growth rate used the eigenvalues of the Leslie Matrix. The dominant eigenvalues can indicate that the population growth rate tends to increase, remain or decrease.

\section{Eigen vector}

Eigen vector for an $n \times n$ matrix $A$, scalars $\lambda$ and vectors $x_{n x 1} \neq 0$ satisfying $A \boldsymbol{x}=\lambda \boldsymbol{x}$ are

called eigenvalues and eigenvectors of $A$, respectively, and any such pair, $(\lambda, \boldsymbol{x})$ is called an eigen pair of $A$. The set of distinct eigenvalues, denoted by $\sigma(A)$, is called the spectrum of $A$.

- $\lambda \in \sigma(\mathrm{A}) \Leftrightarrow \mathrm{A}-\lambda I$ is singular $\Leftrightarrow \operatorname{det}(A-\lambda I)=0$ (Carnia et al., 2019)

Theorem 2.2.2.1.1(Sanusi \& Ridiawati, 2018)

A matrix has a single positive eigenvalue $\lambda_{1}$, this eigenvalue has a multiplicity of one and an eigenvector $x_{1}$ where all entries are positive.

Theorem 2.2.2.1.2(Sanusi \& Ridiawati, 2018).

If $\lambda_{1}$ is a single positive eigenvalue from a Leslie Matrix and $\lambda_{k}$ is any real number eigenvalues or complex numbers from the Leslie Matrix, then $\left|\lambda_{k}\right| \leq \lambda_{1}$

Definition 2.2.1.2 (Sanusi \& Ridiawati, 2018).

Given that $\lambda_{1}, \lambda_{2}, \ldots, n$ is the eigenvalue of matrix $\mathrm{A}$ of size $n \times n, \lambda_{1}$ is said to be the dominant eigenvalue of $\mathrm{A}$ if:

$$
\left|\lambda_{1}\right|>\left|\lambda_{i}\right| \text { with } i=1,2,3 \ldots, n
$$




$$
n(1+p)=\lambda_{1} n(t+(p-1))
$$

From Equation (13) it is obtained that, if for any $p$ which represents the next year in the population and it is known that $\lambda_{1}=1$ is the dominant eigenvalue of the Leslie Matrix, it can be concluded that the next age distribution vector is always the same as the previous age vector. This results in:

1. If it is known that $\lambda_{1}<1$, then the population growth will tend to decline.

2. If it is known that $\lambda_{1}=1$, then the population growth will tend to remain constant.

3. If it is known that $\lambda_{1}>1$, then the population growth will tend to increase.

\section{Results and Discussion}

The Leslie Matrix has characteristics in its formation, which differentiates it from the form of the Matrix in general. The first characteristic of the Leslie Matrix lies in the element of the Leslie Matrix which is only determined by two factors, which is the level of fertility and the level of survival. Second, the arrangement of the elements of the Leslie Matrix, in the first row the elements of the Leslie Matrix contain the entries of the fertility level, and the sub-diagonal element contains the entries of the survival rate. The other elements are zero (Sanusi \& Ridiawati, 2018).

To determine the prediction of population growth up to $p$ the next year, several developments were carried out(Sanusi \& Ridiawati, 2018).

$$
\begin{aligned}
& n(t+1)=A n(t) \\
& n(t+2)=A n(t+1)=A A n(t)=A^{2} n(t) \\
& n(t+3)=A n(t+2)=A A^{2} n(t)=A^{3} n(t) \\
& n(t+4)=A n(t+3)=A A^{3} n(t)=A^{4} n(t) \\
& n(t+5)=A n(t+4)=A A^{4} n(t)=A^{5} n(t) \\
& \vdots \\
& n(t+p)=A n(t+(p-1))=A A^{p-1} n(t)=A^{p} n(t)
\end{aligned}
$$

So that for $p$ next year, the population growth model is as in equation (15)

$$
n(t+p)=A^{p} n(t)
$$

Which is:

$n(t+p):$ Population vector that contains the predicted population in the current class $(t+p)$

$A \quad$ : A Leslie Matrix of size $n \times n$

$n(t)$ : population vector containing the population in the age class at time $t$

For the application of the Leslie Matrix, the number of female population data is given in West Java Province in 2018 and 2019 was group by age, is shown in Table 3. 


\begin{tabular}{ccc}
\hline Age Group & $\mathbf{2 0 1 8}$ & $\mathbf{2 0 1 9}$ \\
\cline { 2 - 3 } $\mathbf{0}-\mathbf{4}$ & $\begin{array}{c}\text { Population } \\
\text { (Women) }\end{array}$ & $\begin{array}{c}\text { Population } \\
\text { (Women) }\end{array}$ \\
\hline $\mathbf{5}-\mathbf{9}$ & 2124452.0 & 2115954.0 \\
\hline $\mathbf{1 0 - 1 4}$ & 2104541.0 & 2122338.0 \\
\hline $\mathbf{1 5}-\mathbf{1 9}$ & 2016745.0 & 2023494.0 \\
\hline $\mathbf{2 0}-\mathbf{2 4}$ & 2021765.0 & 2020185.0 \\
\hline $\mathbf{2 5}-\mathbf{2 9}$ & 2030744.0 & 2039168.0 \\
\hline $\mathbf{3 0}-\mathbf{3 4}$ & 1954176.0 & 1971289.0 \\
\hline $\mathbf{3 5}-\mathbf{3 9}$ & 1886055.0 & 1893803.0 \\
\hline $\mathbf{4 0}-\mathbf{4 4}$ & 1881773.0 & 1885988.0 \\
\hline $\mathbf{4 5}-\mathbf{4 9}$ & 1773433.0 & 1802637.0 \\
\hline $\mathbf{5 0}-\mathbf{5 4}$ & 1577476.0 & 1617102.0 \\
\hline $\mathbf{5 5}-\mathbf{5 9}$ & 1332937.0 & 1377890.0 \\
\hline $\mathbf{6 0}-\mathbf{6 4}$ & 1079022.0 & 1122713.0 \\
\hline $\mathbf{6 5}-\mathbf{6 9}$ & 809776.0 & 856075.0 \\
\hline $\mathbf{7 0}-\mathbf{7 4}$ & 562852.0 & 593587.0 \\
\hline $\mathbf{7 5 +}$ & 397213.0 & 413028.0 \\
\hline Total & 476292.0 & 498760.0 \\
\hline & 24031252.0 & 24354011.0 \\
\hline & &
\end{tabular}

Table 4. Grouping of women based on age class.

\begin{tabular}{|c|c|c|c|}
\hline \multirow[t]{2}{*}{ Age Group } & 2018 & \multirow{2}{*}{$\begin{array}{c}\text { Number of Children born } \\
\text { in 2018-2019 }\end{array}$} & \multirow{2}{*}{$\begin{array}{c}\mathbf{2 0 1 9} \\
\text { Population } \\
\text { (Female) }\end{array}$} \\
\hline & $\begin{array}{c}\text { Population } \\
\text { (Female) }\end{array}$ & & \\
\hline $0-4$ & 2124452.0 & 0 & 2115954.0 \\
\hline $5-9$ & 2104541.0 & 0 & 2122338.0 \\
\hline $10-14$ & 2016745.0 & 0 & 2023494.0 \\
\hline $15-19$ & 2021765.0 & 72784.0 & 2020185.0 \\
\hline $20-24$ & 2030744.0 & 225413.0 & 2039168.0 \\
\hline $25-29$ & 1954176.0 & 269676.0 & 1971289.0 \\
\hline $30-34$ & 1886055.0 & 213124.0 & 1893803.0 \\
\hline 35 - 39 & 1881773.0 & 118552.0 & 1885988.0 \\
\hline $40-44$ & 1773433.0 & 35469.0 & 1802637.0 \\
\hline $45-49$ & 1577476.0 & 6310.0 & 1617102.0 \\
\hline $50-54$ & 1332937.0 & 0 & 1377890.0 \\
\hline $55-59$ & 1079022.0 & 0 & 1122713.0 \\
\hline $60-64$ & 809776.0 & 0 & 856075.0 \\
\hline $65-69$ & 562852.0 & 0 & 593587.0 \\
\hline $70-74$ & 397213.0 & 0 & 413028.0 \\
\hline $75+$ & 476292.0 & 0 & 498760.0 \\
\hline Total & 24031252.0 & 941328.0 & 24354011.0 \\
\hline
\end{tabular}

The Leslie Matrix Model can be used to determine the number of female population in 2 the next year (Marzuki et al., 2017). The female population can be grouped by age class as in Table 4 . 
Using a Matrix Leslie, the female population is divided into several age class intervals, with the female fertility age interval of 15 - 44 years. To calculate the number of female populations using the Leslie Matrix method, it is effect by the level of fertility $\left(a_{i}\right)$ and survival rate $\left(b_{i}\right)$. The following is a final step to predict the number and rate of female population growth in West Java Province in 2021.

Table 5. Fertility and Life Resilience for Women

\begin{tabular}{ccc}
\hline Age Group & $a_{i}$ & $b_{i}$ \\
\hline $\mathbf{0}-\mathbf{4}$ & 0 & 0.991 \\
\hline $\mathbf{5}-\mathbf{9}$ & 0 & 0.958 \\
\hline $\mathbf{1 0 - 1 4}$ & 0 & 1.002 \\
\hline $\mathbf{1 5}-\mathbf{1 9}$ & 0.036 & 1.004 \\
\hline $\mathbf{2 0}-\mathbf{2 4}$ & 0.111 & 0.962 \\
\hline $\mathbf{2 5}-\mathbf{2 9}$ & 0.138 & 0.965 \\
\hline $\mathbf{3 0}-\mathbf{3 4}$ & 0.113 & 0.998 \\
\hline $\mathbf{3 5}-\mathbf{3 9}$ & 0.063 & 0.942 \\
\hline $\mathbf{4 0}-\mathbf{4 4}$ & 0.020 & 0.890 \\
\hline $\mathbf{4 5}-\mathbf{4 9}$ & 0.004 & 0.845 \\
\hline $\mathbf{5 0}-\mathbf{5 4}$ & 0 & 0.810 \\
\hline $\mathbf{5 5}-\mathbf{5 9}$ & 0 & 0.750 \\
\hline $\mathbf{6 0}-\mathbf{6 4}$ & 0 & 0.695 \\
\hline $\mathbf{6 5}-\mathbf{6 9}$ & 0 & 0.706 \\
\hline $\mathbf{7 0}-\mathbf{7 4}$ & 0 & 1.204 \\
\hline $\mathbf{7 5 +}$ & 0 & - \\
\hline Total & & \\
\hline & & \\
\hline & & \\
\hline & & \\
\hline & & \\
\hline & 0.964 \\
\hline
\end{tabular}

Based on Table 5, the following Leslie matrix is obtained:

$$
A=\left[\begin{array}{cccccccccccccccc}
0 & 0 & 0 & 0.036 & 0.111 & 0.138 & 0.113 & 0.063 & 0.020 & 0.004 & 0 & 0 & 0 & 0 & 0 & 0 \\
0.991 & 0 & 0 & 0 & 0 & 0 & 0 & 0 & 0 & 0 & 0 & 0 & 0 & 0 & 0 & 0 \\
0 & 0.958 & 0 & 0 & 0 & 0 & 0 & 0 & 0 & 0 & 0 & 0 & 0 & 0 & 0 & 0 \\
0 & 0 & 1.002 & 0 & 0 & 0 & 0 & 0 & 0 & 0 & 0 & 0 & 0 & 0 & 0 & 0 \\
0 & 0 & 0 & 1.004 & 0 & 0 & 0 & 0 & 0 & 0 & 0 & 0 & 0 & 0 & 0 & 0 \\
0 & 0 & 0 & 0 & 0.962 & 0 & 0 & 0 & 0 & 0 & 0 & 0 & 0 & 0 & 0 & 0 \\
0 & 0 & 0 & 0 & 0 & 0.965 & 0 & 0 & 0 & 0 & 0 & 0 & 0 & 0 & 0 & 0 \\
0 & 0 & 0 & 0 & 0 & 0 & 0.998 & 0 & 0 & 0 & 0 & 0 & 0 & 0 & 0 & 0 \\
0 & 0 & 0 & 0 & 0 & 0 & 0 & 0.942 & 0 & 0 & 0 & 0 & 0 & 0 & 0 & 0 \\
0 & 0 & 0 & 0 & 0 & 0 & 0 & 0 & 0.890 & 0 & 0 & 0 & 0 & 0 & 0 & 0 \\
0 & 0 & 0 & 0 & 0 & 0 & 0 & 0 & 0 & 0.845 & 0 & 0 & 0 & 0 & 0 & 0 \\
0 & 0 & 0 & 0 & 0 & 0 & 0 & 0 & 0 & 0 & 0.810 & 0 & 0 & 0 & 0 & 0 \\
0 & 0 & 0 & 0 & 0 & 0 & 0 & 0 & 0 & 0 & 0 & 0.750 & 0 & 0 & 0 & 0 \\
0 & 0 & 0 & 0 & 0 & 0 & 0 & 0 & 0 & 0 & 0 & 0 & 0.695 & 0 & 0 & 0 \\
0 & 0 & 0 & 0 & 0 & 0 & 0 & 0 & 0 & 0 & 0 & 0 & 0 & 0.706 & 0 & 0 \\
0 & 0 & 0 & 0 & 0 & 0 & 0 & 0 & 0 & 0 & 0 & 0 & 0 & 0 & 1.204 & 0
\end{array}\right]
$$

It is known that $p=2$ which means the next two years and $t+1$ where $n(t)$ is the number of women in 2019 as the initial population number.

By using equation (15) it is obtained: 


$$
\begin{aligned}
& n(t+p)=A^{p} n(t) \\
& n(1+2)=A^{2} n(t) \\
& n(3)=A^{2} n(1)
\end{aligned}
$$

$$
n(3)=\left[\begin{array}{cccccccccccccccc}
0 & 0 & 0 & 0.036 & 0.111 & 0.138 & 0.113 & 0.063 & 0.020 & 0.004 & 0 & 0 & 0 & 0 & 0 & 0 \\
0.991 & 0 & 0 & 0 & 0 & 0 & 0 & 0 & 0 & 0 & 0 & 0 & 0 & 0 & 0 & 0 \\
0 & 0.958 & 0 & 0 & 0 & 0 & 0 & 0 & 0 & 0 & 0 & 0 & 0 & 0 & 0 & 0 \\
0 & 0 & 1.002 & 0 & 0 & 0 & 0 & 0 & 0 & 0 & 0 & 0 & 0 & 0 & 0 & 0 \\
0 & 0 & 0 & 1.004 & 0 & 0 & 0 & 0 & 0 & 0 & 0 & 0 & 0 & 0 & 0 & 0 \\
0 & 0 & 0 & 0 & 0.962 & 0 & 0 & 0 & 0 & 0 & 0 & 0 & 0 & 0 & 0 & 0 \\
0 & 0 & 0 & 0 & 0 & 0.965 & 0 & 0 & 0 & 0 & 0 & 0 & 0 & 0 & 0 & 0 \\
0 & 0 & 0 & 0 & 0 & 0 & 0.998 & 0 & 0 & 0 & 0 & 0 & 0 & 0 & 0 & 0 \\
0 & 0 & 0 & 0 & 0 & 0 & 0 & 0.942 & 0 & 0 & 0 & 0 & 0 & 0 & 0 & 0 \\
0 & 0 & 0 & 0 & 0 & 0 & 0 & 0 & 0.890 & 0 & 0 & 0 & 0 & 0 & 0 & 0 \\
0 & 0 & 0 & 0 & 0 & 0 & 0 & 0 & 0 & 0.845 & 0 & 0 & 0 & 0 & 0 & 0 \\
0 & 0 & 0 & 0 & 0 & 0 & 0 & 0 & 0 & 0 & 0.810 & 0 & 0 & 0 & 0 & 0 \\
0 & 0 & 0 & 0 & 0 & 0 & 0 & 0 & 0 & 0 & 0 & 0.750 & 0 & 0 & 0 & 0 \\
2122338 \\
2023494 \\
2020185 \\
2039168 \\
1971289 \\
1893803 \\
1885988 \\
1802637 \\
1617102 \\
1377890 \\
1122713 \\
0 & 0 & 0 & 0 & 0 & 0 & 0 & 0 & 0 & 0 & 0 & 0 & 0.695 & 0 & 0 & 0 \\
0 & 0 & 0 & 0 & 0 & 0 & 0 & 0 & 0 & 0 & 0 & 0 & 0 & 0.706 & 0 & 0 \\
856075 \\
593.87 \\
413028 \\
498760
\end{array}\right]
$$

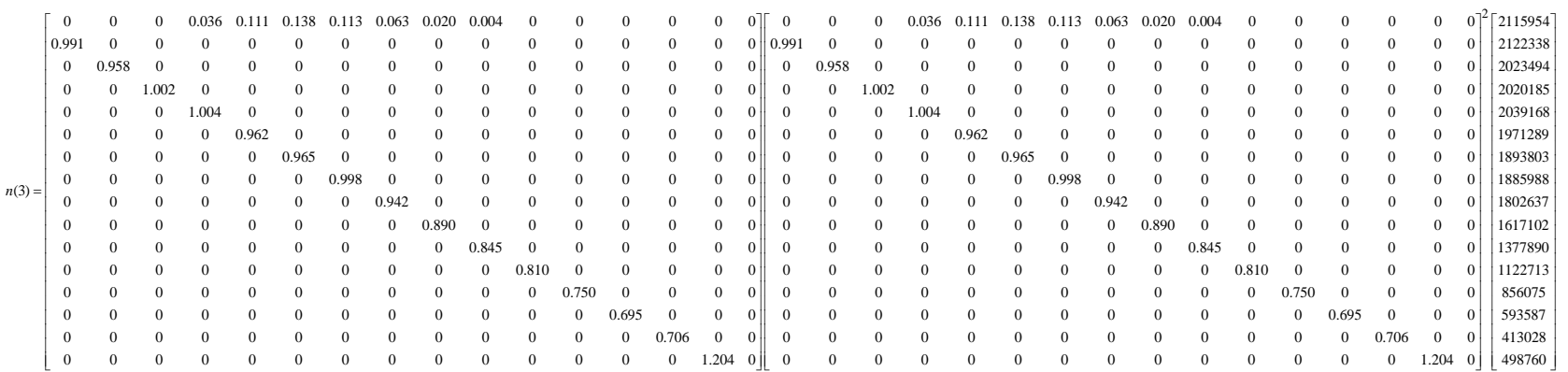

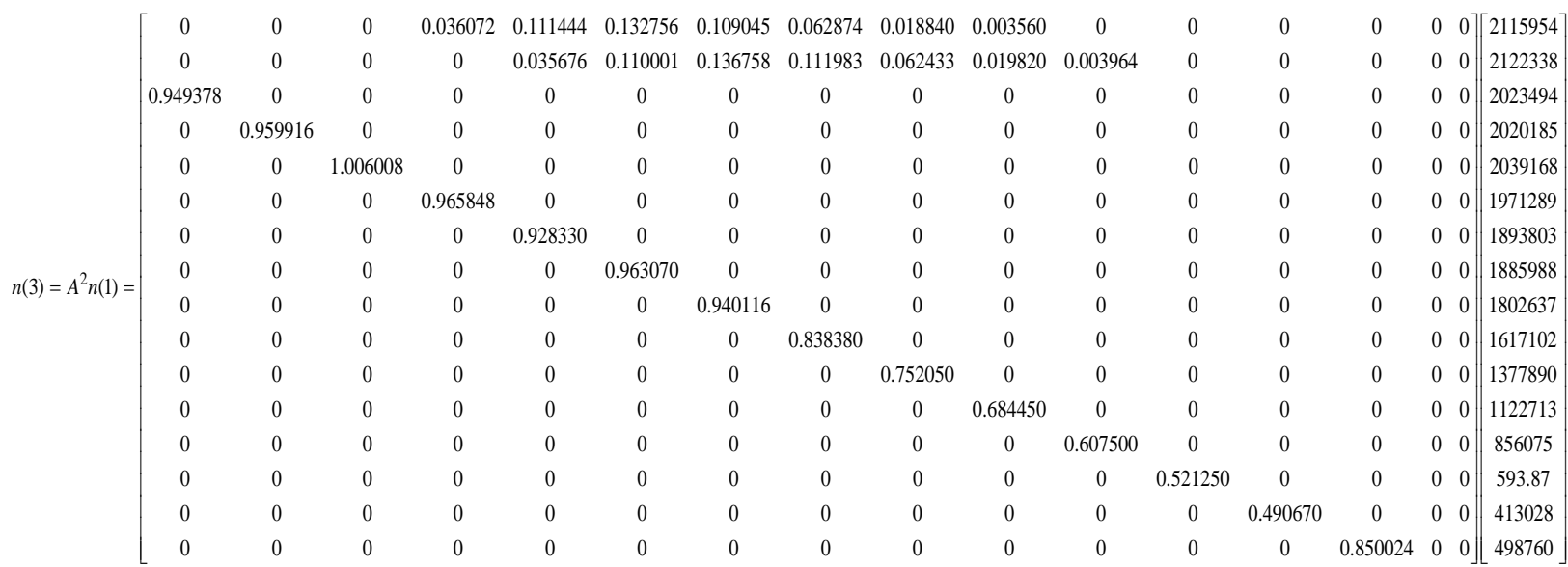




$$
n(3)=\left[\begin{array}{l}
9.448203401 * 10^{5} \\
9.379322681 * 10^{5} \\
2.008840177 * 10^{6} \\
2.037266204 * 10^{6} \\
2.035651152 * 10^{6} \\
1.951191642 * 10^{6} \\
1.893020829 * 10^{6} \\
1.898489297 * 10^{6} \\
1.780394501 * 10^{6} \\
1.581174619 * 10^{6} \\
1.355673156 * 10^{6} \\
1.106825464 * 10^{6} \\
8.370681750 * 10^{5} \\
5.852141512 * 10^{5} \\
4.200503202 * 10 \\
5.045631961 * 10
\end{array}\right]
$$

So, the predicate for the total number of female populations in 2021 in West Java Province is 21878175.0 people. This indicates a decrease of 2475836.0 people from the total female population in 2019 which amounted to 24354011.0 people.

Next, the population growth rate will be predicted using the eigenvalue $(\lambda)$ from the Leslie Matrix. To calculate the eigenvalues of the Leslie Matrix the equation is used $(\operatorname{det}(\lambda I-A)=0)$.

$\lambda I-A=\left[\begin{array}{cccccccccccccccc}\lambda & 0 & 0 & -0.036 & -0,111 & -0.138 & -0.113 & -0.063 & -0.020 & -0.004 & 0 & 0 & 0 & 0 & 0 & 0 \\ -0.991 & \lambda & 0 & 0 & 0 & 0 & 0 & 0 & 0 & 0 & 0 & 0 & 0 & 0 & 0 & 0 \\ 0 & -0.958 & \lambda & 0 & 0 & 0 & 0 & 0 & 0 & 0 & 0 & 0 & 0 & 0 & 0 & 0 \\ 0 & 0 & -1.002 & \lambda & 0 & 0 & 0 & 0 & 0 & 0 & 0 & 0 & 0 & 0 & 0 & 0 \\ 0 & 0 & 0 & -1.004 & \lambda & 0 & 0 & 0 & 0 & 0 & 0 & 0 & 0 & 0 & 0 & 0 \\ 0 & 0 & 0 & 0 & -0.962 & \lambda & 0 & 0 & 0 & 0 & 0 & 0 & 0 & 0 & 0 & 0 \\ 0 & 0 & 0 & 0 & 0 & -0.965 & \lambda & 0 & 0 & 0 & 0 & 0 & 0 & 0 & 0 & 0 \\ 0 & 0 & 0 & 0 & 0 & 0 & -0.998 & \lambda & 0 & 0 & 0 & 0 & 0 & 0 & 0 & 0 \\ 0 & 0 & 0 & 0 & 0 & 0 & 0 & -0.942 & \lambda & 0 & 0 & 0 & 0 & 0 & 0 & 0 \\ 0 & 0 & 0 & 0 & 0 & 0 & 0 & 0 & -0.890 & \lambda & 0 & 0 & 0 & 0 & 0 & 0 \\ 0 & 0 & 0 & 0 & 0 & 0 & 0 & 0 & 0 & -0.845 & \lambda & 0 & 0 & 0 & 0 & 0 \\ 0 & 0 & 0 & 0 & 0 & 0 & 0 & 0 & 0 & 0 & -0.810 & \lambda & 0 & 0 & 0 & 0 \\ 0 & 0 & 0 & 0 & 0 & 0 & 0 & 0 & 0 & 0 & 0 & -0.750 & \lambda & 0 & 0 & 0 \\ 0 & 0 & 0 & 0 & 0 & 0 & 0 & 0 & 0 & 0 & 0 & 0 & -0.695 & \lambda & 0 & 0 \\ 0 & 0 & 0 & 0 & 0 & 0 & 0 & 0 & 0 & 0 & 0 & 0 & 0 & -0.706 & \lambda & 0 \\ 0 & 0 & 0 & 0 & 0 & 0 & 0 & 0 & 0 & 0 & 0 & 0 & 0 & 0 & -1.204 & \lambda\end{array}\right]$

From the equation $(\operatorname{det}(\lambda I-A)=0)$ obtained the characteristic equation namely:

$7.161428849 * 10^{10} \lambda^{2}-1.010200420 * 10^{11} \lambda^{3}-1.144255763 * 10^{6} \lambda^{11}+69770.45627 * \lambda^{12}+89.06078174 * \lambda^{14}-1.579139335 * \lambda^{15}$ $+1.012771247 * \lambda^{16}+8.211901272 * 10^{10} \lambda^{4}+1.602947895 * 10^{10} \lambda^{6}-4.271837090 * 10^{9} \lambda^{7}+8.423557463 * 10^{8} \lambda^{8}$

$-1.243965446 * 10^{8} \lambda^{9}+1.380214115 * 10^{7} \lambda^{10}-2.170512893 * 10^{10} \lambda-3034.859598 \lambda^{13}-4.349645602 * 10^{10} \lambda^{5}=0$

The characteristic equation is then solved using the Maple application to obtain the eigenvalues. The eigenvalues obtained are: 


$$
\begin{aligned}
& \lambda_{1}=0, \lambda_{2}=0.9999999789, \lambda_{3}=2.000302900, \lambda_{4}=2.787417096, \\
& \lambda_{5}=3.008913215+0.7262946709 i, \lambda_{6}=3.193556935+1.826364447 i, \\
& \lambda_{7}=3.145921689+3.382873649 i, \lambda_{8}=2.508660167+5.7753739351 i, \\
& \lambda_{9}=-0.2189186659+9.844874354 i, \lambda_{10}=-13.75238029-13.12031173 i, \\
& \lambda_{11}=-0.2189186659-9.844874354 i, \lambda_{12}=2.508660167-5.77373935 i, \\
& \lambda_{13}=3.145921689-3.382873649 i, \lambda_{14}=3.193556935-1.826364447 i, \\
& \lambda_{15}=3.008913215-0.7262946709 i
\end{aligned}
$$

Based on the theorem and definition, 2.2.1.2 the dominant eigen values are $\lambda_{4}=2.787417096$. That the dominant eigenvalue is greater than one, meaning that this value shows that the It is obtained population growth rate of West Java Province tends to increase.

\section{Conclussion}

Based on the results and discussion, the following conclusions were obtained:

1. The Leslie matrix with its characteristics has been able to provide problem solving solutions, in this study it is used to predict the number of female population in West Java Province in 2021. Calculation of female population growth using the Leslie Matrix with the equation

$$
n(t+p)=A^{p} n(t)
$$

can count up to $p$ the following year.

2. The population growth rate of West Java Province can fluctuate but has an upward trend.

\section{References}

Anggreini, D. (2017). The Female Population Growth Projection Year 2021 in Trenggalek Regency by Leslie Matrix Model on the Birth Rate and Life Expectancy. Biology, Medicine, \& Natural Product Chemistry, 6(2), $37-45$.

BPS. (2019). Jumlah Penduduk Menurut Kelompok Umur dan Jenis Kelamin Tahun 2018. https://Www.Bps.go.id.

Carnia, E., Anggriani, N., Gustyana, M., \& Supriatna, A. K. (2019, November). Type the title of your paper here mathematical properties of $\mathrm{n} \times \mathrm{n}$ nonnegative matrix: case of irreducible Leslie matrix. In Journal of Physics: Conference Series (Vol. 1280, No. 2, p. 022048). IOP Publishing.

Chandler, G. T., Cary, T. L., Bejarano, A. C., Pender, J., \& Ferry, J. L. (2004). Population consequences of fipronil and degradates to copepods at field concentrations: An integration of life cycle testing with Leslie matrix population modeling. Environmental science \& technology, 38(23), 6407-6414.

Coccia, M. (2018). The relation between terrorism and high population growth. Journal of Economics and Political Economy, 5(1), 84-104.

Cortes, E. (2020). Preliminary Estimates of Vital Rates and Population Dynamics Parameters of Porbeagle Shark in the Northwest Atlantic Ocean. Collect. Vol. Sci. Pap. ICCAT, 76(10), 164-172.

Hansen, P. E. (1989). Leslie matrix models. Mathematical Population Studies, 2(1), 37-67. 
Li, S., Yang, Z., Li, H., \& Shu, G. (2018). Projection of population structure in China using least squares support vector machine in conjunction with a Leslie matrix model. Journal of Forecasting, 37(2), 225-234.

Marzuki, C. C., Muda, Y., \& Hasanah, N. (2016). Aplikasi Matriks Leslie Untuk Memprediksi Jumlah Dan Laju Pertumbuhan Perempuan Di Provinsi Riau Pada Tahun 2017. Jurnal Sains Matematika dan Statistika, 2(1), $37-48$.

Mauritsson, K. (2020). Effects of PCB on the population growth rate of Baltic grey seals: a toxicokinetictoxicodynamic Leslie matrix model (Doctoral dissertation, MSc thesis. Department o f Biological and Environmental Sciences. Gothenburg University).

Miller, D. H., Clark, B. W., \& Nacci, D. E. (2020). A multidimensional density dependent matrix population model for assessing risk of stressors to fish populations. Ecotoxicology and Environmental Safety, 201(February), 110786.

Monte, L. (2018). Nonlinear Leslie models for the assessment of the effects of stressors on the development of wild populations: reviewing of the basic properties. Journal of Interdisciplinary Mathematics, 21(1), 83-109.

Rand, T. A., Richmond, C. E., \& Dougherty, E. T. (2020). Modeling the combined impacts of host plant resistance and biological control on the population dynamics of a major pest of wheat. Pest management science, 76(8), 2818-2828.

Sanusi, W., \& Ridiawati, N. (2018). Matriks Leslie dan Aplikasinya dalam Memprediksi Jumlah dan Laju pertumbuhan Penduduk di Kota Makassar. 1(2), 142-154.

Smit, M. G., Kater, B. J., Jak, R. G., \& Van den Heuvel-Greve, M. J. (2006). Translating bioassay results to field population responses using a Leslie-matrix model for the marine amphipod Corophium volutator. Ecological modelling, 196(3-4), 515-526.

Xie, Y., Yu, H., Lei, X., \& Lin, A. J. (2020). The impact of fertility policy on the actuarial balance of China's urban employee basic medical insurance fund-The selective two-child policy vs. the universal two-child policy. North American Journal of Economics and Finance, 53(10), 101212.

Yuliawati, A., Listiawati, M., Santosa, Y., \& Thohari, A. M. (2019). Optimum sustainable population estimation of Rusa timorensis in Pananjung Pangandaran nature reserve and natural park. Journal of Physics: Conference Series, 1402(3), 8-12. 